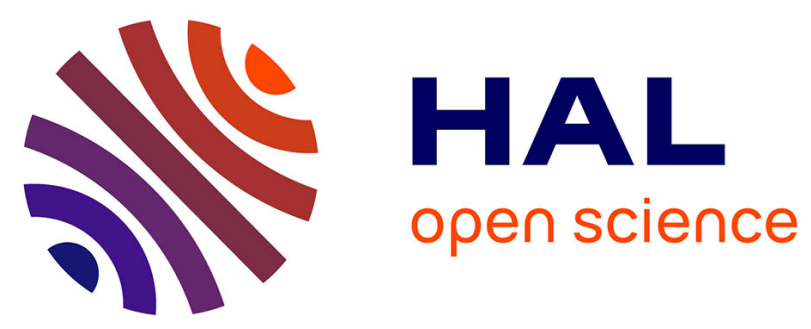

\title{
A Technology for Prediction and Prevention of Freezing of Gait (FOG) in Individuals with Parkinson Disease
}

\author{
Megh Patel, Gottumukala Krishna, Abhijit Das, Uttama Lahiri
}

\section{To cite this version:}

Megh Patel, Gottumukala Krishna, Abhijit Das, Uttama Lahiri. A Technology for Prediction and Prevention of Freezing of Gait (FOG) in Individuals with Parkinson Disease. 16th IFIP Conference on Human-Computer Interaction (INTERACT), Sep 2017, Bombay, India. pp.395-403, 10.1007/9783-319-67687-6_26. hal-01717230

\author{
HAL Id: hal-01717230 \\ https://hal.inria.fr/hal-01717230
}

Submitted on 26 Feb 2018

HAL is a multi-disciplinary open access archive for the deposit and dissemination of scientific research documents, whether they are published or not. The documents may come from teaching and research institutions in France or abroad, or from public or private research centers.
L'archive ouverte pluridisciplinaire $\mathbf{H A L}$, est destinée au dépôt et à la diffusion de documents scientifiques de niveau recherche, publiés ou non, émanant des établissements d'enseignement et de recherche français ou étrangers, des laboratoires publics ou privés. 


\title{
A Technology for Prediction and Prevention of Freezing of Gait (FOG) in Individuals with Parkinson Disease
}

\author{
Megh Patel $^{1}$,Gottumukala Sai Rama Krishna ${ }^{1}$, Abhijit Das $^{2}$, Uttama Lahiri ${ }^{1}$ \\ ${ }^{1}$ Indian Institute of Technology Gandhinagar, Department Of Electrical Engineering, \\ Gandhinagar \\ \{megh2301@gmail.com, gottumukala.sai@iitgn.ac.in \\ , uttama.lahirieiitgn.ac.in\} \\ ${ }^{2}$ AMRI Institute of Neurosciences, Kolkata \\ abhijit.neuro@gmail.com
}

\begin{abstract}
External cueing in the form of visual, auditory or vibratory cue is useful to avoid freezing of gait (FOG) problem commonly experienced by individuals with Parkinson Disease (PD). The currently available technologyassisted solutions are of limited help because of two main issues: (i) the use of accelerometer or gyro-based wearable sensors for prediction of FOG are noise prone and (ii) deliver external cues without any individualization. In our present research, we have designed a low-cost system that can be attached as an add-on module on ordinary walking stick that can (i) predict freezing of gait (ii) deliver visual, auditory and/or vibratory cues in an individualized manner. We conducted a preliminary study with one PD participant. The preliminary results show potential of our system to reduce freezing counts, increase average step length and walk speed of the participant.
\end{abstract}

Keywords: Parkinson's Disease (PD), cues, Freezing of Gait(FOG), Gait Analysis

\section{Introduction}

Globally, approximately $1 \%$ of individuals older than 60 years are reported to be suffering from Parkinson's Disease (PD) [1] which turns out to be more than 10 million people worldwide [2]. Gait abnormality is a hallmark of this disease which is attributed to loss of neurons in substantia nigra of basal ganglia, responsible for generation of dopamine [3]. Freezing of gait (FOG) is a common and debilitating, but largely mysterious, symptom of Parkinson disease with limited treatment options[3]. FOG is characterized by varying combinations of start hesitation, hesitation while walking through narrow spaces and at the time of turning, stop hesitation or hesitation at any point while walking, which often results into fall [3]. Thus, often, the PD individuals suffering from FOG, become dependent on caregivers for community ambula- 
tion, thereby adversely affecting their independent community living and overall quality of life.

Technology-assisted solutions that provide external cues, have been reported to improve walk pattern with reduced / no FOG occurrence during walking in PD patients[4,5]. External cues in the form of visual, auditory or vibratory cues are delivered either in isolation or in combination. Visual cues in the form of transverse lines on the floor [6], 3D staircase painted floor [7], curved end of an inverted walking stick [8], laser lines projected on floor by foot-mounted wearable device [9] have been reported to be useful in improving walk pattern of individuals with PD. Combination of Visual and Auditory cues given by augmented reality based Google glass has also been found to be useful for avoiding FOG in individual with PD [10]. Auditory cues generated by Listenmee mobile based application has been shown to be useful in improving the walk pattern of individual with PD [11]. The Vibratory cue has been shown to contribute to significant improvement in step synchronization in individuals with PD suffering from FOG [12]. For example, Step-synchronized vibratory cue applied to one's feet, such as in PD shoes, has been reported to improve one's walking ability [12].

These currently-existing technology-assisted solutions often suffer from the protocol of delivery of the external cues and / or usage of wired systems. Specifically, most of the systems delivering Visual, Auditory, and / or Vibratory Cues, generate these cues either individually or in combinations continuously, instead of assist-as-needed. For example, most systems generate Vibratory cue in a continuous manner (irrespective of whether this cue is required or not) and delivered alternately to both legs of a person that is often irritating and / or distracting to the person. Additionally, given the spectrum nature of the disorder, often the manifestation of the PD symptoms is highly variable even in an individual, [13] which calls for personalization. There is no existing system to our knowledge that can trigger combinations of the three external cues in an integrated and assist-as-needed manner that is individualized to each person's walking capability. Again, researchers have often used wearable sensors attached to the hands [14] or feet [15] for sensing gait abnormalities. However, the attachment of these sensors can (i) bring in a feeling of being wired, affecting the freedom of movement of the user and (ii) pose a possibility of adding signal noise on account of movement artifacts that may not be associated with one's walking.

Thus, given these limitations, we have designed a Smart Walking Aid System that can be fitted as an add-on module on an ordinary available walking stick and wirelessly trigger peripheral modules to deliver Visual, Auditory and/or Vibratory cues in an integrated, assist-as-needed and individualized manner. Additionally, our proposed system does not use any wearable sensors to sense gait abnormalities of the user. Instead, this intelligently monitors one's walking stick movement profile to predict one's possibility of freezing of gait.

\subsection{Objectives and Scope}

The objectives of this paper are two-fold: (i) present the design of the Smart Walking Aid System and (ii) preliminary validation study with one PD participant. This paper is organized as follows: Section 2 describes the system design Section 3 pre- 
sents Experimental Setup for our study with proposed system, Section 4 presents the results obtained in our study and discussion based on the obtained result. Section 5 presents conclusion and limitation.

\section{System Design}

Our Smart Walking Aid System is composed of two sub-modules, namely (1) Master Controller Module and (2) Vibratory Belt assembly.

\subsection{Master Controller Module}

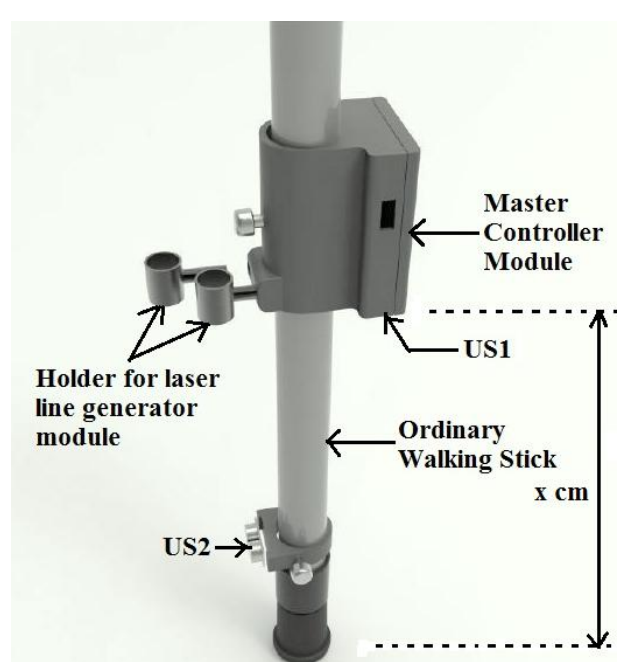

(a)

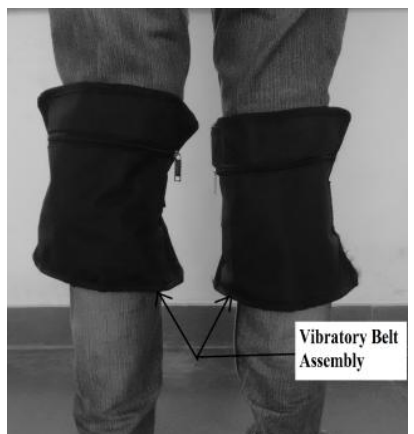

(b)

Fig. 1. Smart Walking Aid System comprising of (a) Master Controller Module (MCM) attached on ordinary walking stick and (b) Vibratory Belt Assembly to be worn on Calf Muscles.

The Fig. 1 shows the Smart Walking Aid System with Master Controller Module (MCM) mounted on an ordinary walking stick at a height of $\mathrm{x} \mathrm{cm}$ from the bottom tip of the stick. The MCM module is a micro-controller based unit operated by a $5 \mathrm{~V}$ regulated supply. MCM receives pulses from two Proximity Sensors (US1 and US2).The US1 is mounted at the bottom of the MCM module and it is used to sense the distance of the stick tip from the ground surface. The US2 is mounted at the stick tip and it is used to sense the user's foot. The MCM module triggers three output peripheral devices, namely, (i) Laser Line Generators to deliver Visual cue by projecting two parallel red colored laser lines (Line1 and Line2) on the floor (ii) Piezoelectric Buzzer to deliver Auditory cue and (iii) Vibratory Belt assembly to deliver 
Vibratory cue. There are two laser line generators attached in holders for laser line generators as shown in Fig. 1 and piezoelectric buzzer is mounted inside MCM.

\subsection{Vibratory Belt Assembly}

The Vibratory Belt assembly is a microcontroller based unit that houses a vibrator unit with Bluetooth connectivity that needs to be wrapped on the calf muscle. The Bluetooth receiver attached with Vibratory Belt Assembly communicates wirelessly with the Bluetooth transmitter of the MCM module to trigger the delivery of vibratory cue based on assist-as-needed.

\subsection{Operation Rationale}

Occurrence of FOG in an individual with PD, while walking is often accompanied with small shuffling steps along with freezing being experienced in hand which in turn changes hand movement profile while walking [14]. Thus, our Smart Walking Aid System computes (i) the time interval between two consecutive contacts of stick tip with the floor surface and (ii) the maximum height (from the floor surface) of the envelope of the profile of the stick tip between two consecutive contacts with the floor surface in real-time, while the user is asked to walk while holding the walking stick in real-time. Based on these two measures, our Smart Walking Aid System calculates the threshold time interval $\left(\Delta t_{T H}\right)$ and height $\left(h_{T H}\right)$, and generates combination of Visual, Auditory and Vibratory cues in an individualized manner to facilitate the individual with PD to overcome FOG while walking. In addition, our Smart Walking Aid System also addresses 'Start Hesitation' by triggering all the three cues for the first $n$ number of steps in an individualized manner.

Consider that for the first $n$ number of steps, let $h_{1}, h_{2}, h_{3}, \ldots h_{n}$ be the maximum height of the profile of the stick tip above the floor surface between consecutive contacts of the stick tip with the floor surface. Also, let $\Delta t_{1}, \Delta t_{2}, \Delta t_{3}, \ldots, \Delta t_{n}$ be the time interval between the consecutive contacts of the stick tip with the floor surface. The system finds the average height $\left(h_{A V G}\right)$ and average time interval $\left(\Delta t_{A V G}\right)$ using Eqns. 1 and 2 . Then the system computes the threshold height $\left(h_{T H}\right)$ and threshold time interval $\left(\Delta t_{T H}\right)$ by using eqns. (3) and (4). The coefficients, ' $\mathrm{w}_{1}$ ' and ' $\mathrm{w}_{2}$ ' can be tuned based on the therapist's feedback. In our case, we chose the values of $\mathrm{w}_{1}=\mathrm{w}_{2}=0.25$ which can be different for different individual.

$$
\begin{aligned}
& h_{A V G}=\frac{1}{n} \sum h_{n} \ldots \ldots \ldots \ldots \ldots(1) \quad \Delta t_{A V G}=\frac{1}{n} \sum t_{n} \ldots \ldots \ldots \ldots \ldots(2) \ldots \ldots(3) \\
& h_{T H}=\left(w_{1}\right) *\left(h_{A V G}\right) \ldots \ldots \ldots\left(t_{T H}=\left(w_{2}\right) *\left(\Delta t_{A V G}\right) \ldots \ldots \ldots(4)\right.
\end{aligned}
$$

While the user walks with the walking stick and the stick tip touches the floor surface, our Smart Walking Aid System projects two red colored laser lines (Line 1 (near the stick tip perpendicular to the stick and in front of user) and Line ${ }_{2}$ (offset by $\mathrm{z}$ units from Line I $_{1}$ and parallel to Line $\left.{ }_{1}\right)$ ) on the floor. When, the stick tip touches the floor surface, auditory cue as a beep-like sound is generated which works as step initiation 
cue. When the user steps on Line 1 , Auditory cue as a coin drop sound is generated which works as feedback cue for correct step.

While the user walks with the walking stick, our Smart Walking Aid System computes instantaneous values of $\Delta t$ and $h$ and checks whether,

$\Delta \mathrm{t}_{\mathrm{AVG}}-\Delta \mathrm{t}_{\mathrm{TH}} \leq \Delta \mathrm{t} \leq \Delta \mathrm{t}_{\mathrm{AVG}}+\Delta \mathrm{t}_{\mathrm{TH}}$

$\mathrm{h}_{\mathrm{AVG}}-\mathrm{h}_{\mathrm{TH}} \leq \mathrm{h} \leq \mathrm{h}_{\mathrm{AVG}}+\mathrm{h}_{\mathrm{TH}}$

Based on these conditions (eqs. 5 and 6), our Smart Walking Aid System predicts abnormality in one's gait pattern. In turn, it triggers Vibratory cue (in an individualized manner) to the user's calf muscles alternatively for the next $n$ steps along with Visual and Auditory cues. That is when person puts walking stick on the floor, system gives one vibratory pulse on one leg and after detection of leg placing on first laser line by US2, system gives vibratory pulse on another leg using Vibratory Belt assembly and that continues until the conditions (5) and (6) are satisfied.

\section{Methods}

\subsection{Participant}

We designed a study in which one male PD participant aged 52 years took part. This participant was recruited from the Civil Hospital, Ahmedabad. He was suffering from PD for the last 10 years with frequent freezing of gait, and was found to be at Stage 3 of the Hoehn and Yahr (H\&Y) scale [16]. The participant was asked to use a walking stick integrated with the smart walking aid system while walking.

\subsection{Experimental Setup}

Our experimental layout was carefully selected to investigate whether our smart walking aid system was capable to address issues of (i) start hesitation, (ii) hesitation while walking through narrow pathway and (iii) hesitation while the user needs to deviate from the straight path. The pathway was $10 \mathrm{~m}$ long. The experimental layout was of three different types, namely, (i) a $3 \mathrm{~m}$ wide straight pathway with no narrow passages and no turns (layout 1), (ii) $3 \mathrm{~m}$ wide straight pathway with a narrow passage of length $0.5 \mathrm{~m}$ and width $1 \mathrm{~m}$ at a distance of 4.5 meters from the start point (layout 2) and (iii) straight pathway of width $3 \mathrm{~m}$ with an obstacle at a distance of 4.5 meters from the start point (layout 3). For layouts 1 and 2, the participant was asked to walk along the straight pathway without turning. For layout 3, the participant was asked to deviate from the straight pathway by taking two turns and walk alongside the obstacle while avoiding it. 


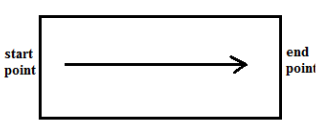

(a)

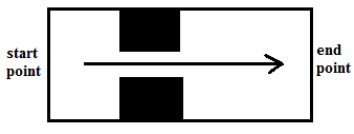

(b)

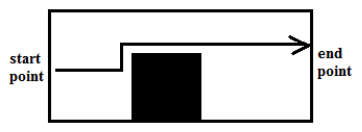

(c)

Fig.3 (a) Layout 1 (straight walking path), (b) Layout 2 (walking path with narrow passage),(c) Layout 3 (walking path requiring one to turn)

The layouts 1, 2 and 3 are shown in Figs. 3(a), (b) and (c). For each layout, there were three walk conditions, such as, walk with smart walking aid system with (i) only visual cue (C1), (ii) combination of visual and auditory cues (C2) and (iii) combination of visual, auditory with vibratory cues (C3). For each condition corresponding to each layout, we computed three indices such as, (1) number of times of freezing of gait (Freezing count), (2) average step length and (3) walking speed.

\section{Results and Discussion}

Our results are discussed below.

\subsection{Implication on Freezing Counts}

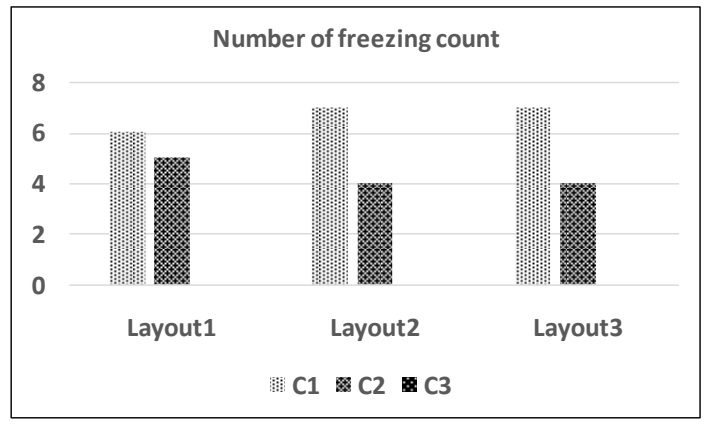

Fig. 3. Implication on Number of freezing counts.

The number of freezing counts reduced from $\mathrm{C} 1$ to $\mathrm{C} 2$ to $\mathrm{C} 3$ with no freezing being observed with all the three cues applied simultaneously by our Smart Walking Aid system. Fig. 3 shows the number of freezing counts observed in different layouts and different conditions $(\mathrm{C} 1, \mathrm{C} 2$ and $\mathrm{C} 3$ ) while our participant walked with the smart walking aid. This possibly infers that vibratory cue delivered in an individualized manner in conjunction with visual and auditory cues have contributed to complete reduction of the freezing for this participant irrespective of start hesitation, hesitation for moving through narrow spaces and turn hesitation. 


\subsection{Implication on Average Step Length}

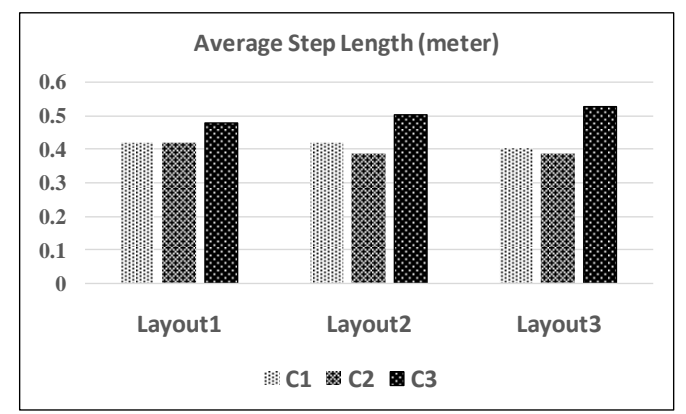

Fig. 4. Implication on Average step length

Previous research confirms that person with Parkinson's disease have fundamental problem in regulating the step length (in meter) during walking, which ultimately results in reduced average step length [18]. The average step length of the PD participant has increased for $\mathrm{C} 3$ compared to that for $\mathrm{C} 1$ and $\mathrm{C} 2$ irrespective of the experimental layout (Fig.4).

\subsection{Implication on Walking Speed}

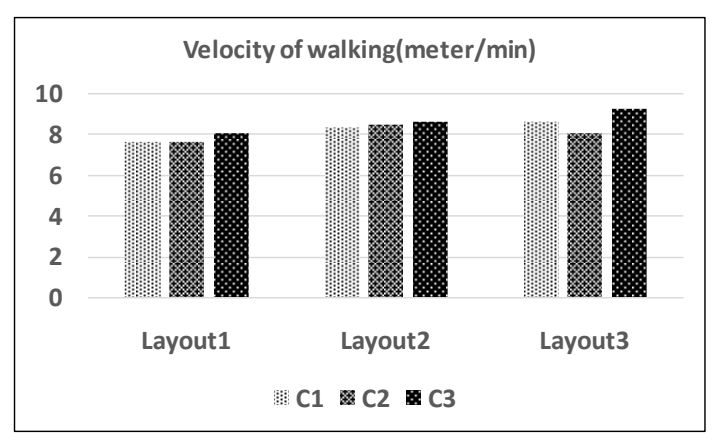

Fig. 5. Implication on walking speed

We also found that $\mathrm{C} 3$ results in improved walking speed which was better than $\mathrm{C} 1$ and C2 irrespective of the study layout (Fig.5).

Thus for all layout, C3 results in reduction in Freezing count, Increase in Step Length and Walking Speed which shows capability of our proposed walking aid system to improve walking pattern of PD Participant. 


\section{Conclusion}

Freezing during walking is one of the most disabling features of individuals with PD [17]. This often gets manifested in terms of reduced average step length (shuffling of steps) along with reduced walking speed. Reduction in freezing counts during walking can improve the gait performance of the individual. In turn, this can lead to increased step length and walking speed. In our present study, we have designed a smart walking aid system that can be connected as an add-on module onto an ordinary walking stick. The system can predict possibility of freezing in one's gait pattern by sensing the profile of the stick tip of the walking stick held by the person during walking. Upon detection of possibility of FOG, , the system can deliver visual, auditory and/or vibratory cues in an individualized manner. Preliminary results of a study carried out with a participant with PD showed the potential of the system to contribute to reducing the number of freezing counts and increasing the average step length and walk speed.

Though the results of our study are promising, yet the study suffers from certain limitations. One of the limitations is the small sample size. The other limitation was restricted study environment. For example, the study was carried out indoors. Thus, questions such as, the use of red colored laser lines as visual cue and intensity of the audio tone used might pose restrictions as far as outdoor study environment is concerned.

In future, we plan to have a randomized and controlled study with a larger number of participants for a longer duration. Also, we plan to use our system outdoors where we might need to replace red-colored laser lines with different colored lines, tune the intensity of audio tone to be audible even in the noisy surroundings, as specified by the user. Also, we plan to make provision of delivering the audio cue to the user using a headset.

From the preliminary study carried out with this system, we hope that the cost-effective, individualized and user-friendly walking aid system can potentially bring about a paradigm shift in healthcare related to Parkinson.

\section{References}

1. Robert A Hauser et al. 2016. "Parkinson disease: Practice essentials, background, anatomy". Retrieved Jun 28, 2016 from http://emedicine.medscape.com/article/1831191overview.

2. P. D. Foundation 2016. "Statistics on Parkinson's - Parkinson's disease foundation" Retrieved Jun 28, 2016 from http://www.pdf.org/en/parkinson_statistics.

3. Okuma, Yasuyuki. "Freezing of gait in Parkinson's disease." Journal of neurology 253.7 (2006): vii27-vii32. 
4. Tamar C. Rubinstein,Nir Giladi and Jeffrey M. Hausdorff.2002. The power of cueing to circumvent dopamine deficits: A review of physical therapy treatment of gait disturbances in Parkinson's disease. Movement Disorders 17,6(2002),1148-1160.

5. I Lim, E van Wegen, C de Goede, M Deutekom, A Nieuwboer, A Willems, D Jones, L Rochester and G Kwakkel.2005. Effects of external rhythmical cueing on gait in patients with Parkinson's disease: A systematic review. Clinical Rehabilitation 19,7(2005),695713.

6. Gwyn N. Lewis, Winston D. Byblow and Sharon E. Walt.2000.Stride length regulation in Parkinson's disease: the use of extrinsic, visual cues. Brain, A journal of Neurology 123,10(2000), 2077-2090.

7. Mileha Soneji. 2015. Empathy is the key to great innovation. Video. (February 2015). Retrieved September 12, 2016 from https://www.ted.com/speakers/mileha_soneji.

8. Mark A. Dietz, Christopher G. Goetz and Glenn T. Stebbins.1990. Evaluation of a modified inverted walking stick as a treatment for parkinsonian freezing episodes. Movement Disorders 5,3(1990),243-247.

9. Yan Zhao, Stefan Ramesberger, Urban M. Fietzek, Lorenzo T. D'Angelo and Tim. C. Lüth.2013. A novel wearable laser device to regulate stride length in Parkinson's disease. In 35th Annual IEEE Conference of the Engineering in Medicine and Biology Society (EMBC).IEEE,5895-5898.

10. Roisin McNaney, John Vines, Daniel Roggen, Madeline Balaam, Pengfei Zhang, Ivan Poliakov and Patrick Olivier.2014. Exploring the acceptability of google glass as an everyday assistive device for people with parkinson's In 32nd annual ACM conference on Human factors in computing systems.ACM,2551-2554.

11. William Omar Contreras Lopez, Carlos Andres Escalante Higuera, Erich Talamoni Fonoff ,Carolina de Oliveira Souza, Ulrich Albicker and Jairo Alberto Espinoza Martinez.2014. Listenmee ${ }^{\circledR}$ and Listenmee ${ }^{\circledR}$ smartphone application: Synchronizing walking to rhythmic auditory cues to improve gait in Parkinson's disease. Human Movement Science 37(2014), 147-156.

12. Kyle N. Winfree, Ingrid Pretzer-Aboff, David Hilgart, Rajeev Aggarwal, Madhuri Behari, and Sunil K. Agrawal.2013. The effect of step-synchronized vibration on patients with Parkinson's disease: Case studies on subjects with freezing of gait or an implanted deep brain stimulator. IEEE Transactions on Neural Systems and Rehabilitation Engineering 21,5(2013), 806-811

13. Parkinson's Disease Foundation, http://www.pdf.org/en/symptoms.

14. Sinziana Mazilu, Ulf Blanke and Gerhard Tröster.2015. Gait, wrist, and sensors: Detecting freezing of gait in Parkinson's disease from wrist movement In IEEE International Conference on Pervasive Computing and Communication Workshops.IEEE,579-584.

15. E. Jovanov, E. Wang, L. Verhagen, M. Fredrickson and R. Fratangelo.2009. deFOG-A real time system for detection and unfreezing of gait of Parkinson's patients In IEEE Annual International Conference of the Engineering in Medicine and Biology Societ,IEEE,5151-5154.

16. R. Bhidayasiri and D. Tarsy.2012.Parkinson's Disease: Hoehn and Yahr Scale. Movement Disorders: A Video Atlas. Humana Press, 4-5.

17. Lamberti, Paolo, Silvia Armenise, Vincenzo Castaldo, Michele de Mari, G. Iliceto, P. Tronci, and L. Serlenga. "Freezing gait in Parkinson's disease." European neurology 38, no. 4 (1997): 297-301.

18. Williams, April J., Daniel S. Peterson, and Gammon M. Earhart. "Gait coordination in Parkinson disease: effects of step length and cadence manipulations." Gait \& posture 38.2 (2013): 340-344. 